ГРНТИ: 06.54.31

DOI: $10.14451 / 1.183 .44$

JEL-коды: 01, 03, 032

\title{
МЕХАНИЗМЫ РАЗВИТИЯ ТЕХНОПАРКОВ КАК ИНСТРУМЕНТА ТРАНСФЕРА ИННОВАЦИОННЫХ ТЕХНОЛОГИЙ
}

\author{
(c) 2020 Завьялова Надежда Борисовна \\ кандидат технических наук, доцент \\ Российский экономический университет им. Г.В. Плеханова, Россия, Москва \\ Email: Zavyalova.nb@rea.ru \\ (c) 2020 Андреева Арина Михайловна \\ Российский экономический университет им. Г.В. Плеханова, Россия, Москва \\ Email: AAM.dot@mail.ru
}

В статье рассмотрены механизмы развития технопарков, обеспечивающие интеграцию ресурсов регионов для вовлечения малого и среднего предпринимательства в процессы создания и практического внедрения инноваций в промышленность. Базой такого механизма должны являться сотрудничество вузов, научно-исследовательских организаций, предприятий промышленности, инвесторов в структурах технопарков на постоянной основе и их взаимодействие посредством ИТ-платформ.

Ключевые слова: технопарки, малое и среднее предпринимательство, организация взаимодействия участников технопарков

\section{Введение}

Развитие научно-технического прогресса во второй половине XX века способствовали необходимости более тесного взаимодействия науки, технологий и промышленности. Новые проекты рождались из научных исследований и требовали наличия производственного оборудования, способного трансформировать теоретические разработки в инновационный продукт. С этой целью в России стали создаваться центры, где наука и технологии объединились - технопарки [4,5]. Международная ассоциация технопарков определяет технологический парк как организацию, управляемую специалистами, главной целью которой является увеличение благосостояния местного сообщества посредством продвижения инновационной культуры, а также состязательности инновационного бизнеса и научных организаций". Эта цель обеспечивается путем управления потоками знаний и технологий между университетами, научноисследовательскими институтами, компаниями и рынками, созданием условий для роста инновационных компаний с применением Spin-off процессов. Эффективная деятельность технопарков, как свидетельствует зарубежный опыт, способствует росту успешных инновационных проектов и, как следствие, росту прибыли компаний, увеличению доходов населения, развитию промышленности регионов и страны в целом. Создание технопарков приводит к улучшению предпринимательской инфраструктуры, научного и производственного потенциала места, где он создается, позволяет снизить степень экономического неравенства регионов.

В России в области развития технопарков как системы трансфера технологий существует ряд проблем, решение которых крайне необходимо. К их числу относятся (1) неточности и несогласованность в описании и трактовке самого понятия «технологический парк (технопарк)» даже на уровне нормативно-правовой базы $[1,2,3]^{* *} ;$ (2) географическая неравномерность размещения технопарков; (3) отсутствие четко различимых функциональных задач между различными структурами в системе поддержки малого и среднего предпринимательства (МСП); (4) не достаточно благоприятные правовые и экономические условия для взаимодействия всех участников инновационной деятельности; (5) отсутствие эффективной бизнес-модели технопарка, способной обеспечить управление по-

\footnotetext{
"IASP.- Режим доступа:: https:/www.iasp.ws/our-industry/the-role-of-stps-and-areas-of-innovation

** В данном исследовании технопарк рассматривается как управляемый управляющей компанией комплекс объектов коммунальной, транспортной и технологической инфраструктуры, обеспечивающий полный цикл услуг по размещению и развитию резидентов технопарков в соответствии с ГОСТ Р 56425-2015
} 
токами знаний и осуществить трансфер новых технологий в промышленность др.

В рамках данного исследования ставится задача выявления механизма трансфера инновационных технологий и вовлечении малого и среднего предпринимательства в процесс создания и коммерциализации инновационной продукции.

\section{Анализ развития технопарков в России}

Первые крупные технопарки в России начали появляться в 1990-х годах. Именно в этот период был открыт совместно с Томским государственным университетом Томский технопарк. В дальнейшем наблюдался рост числа технопарков (1990 г.- 2 технопарка, 1991 г.-8, 1992 г.- 24, 1993 г.- 43), однако из них закрылось, что обусловлено отсутствием на тот момент нормативно-правовой базы и целенаправленной поддержки со стороны государства. Второй этап активного создания технопарков приходится на период с 2006 г. по 2014 г., что связано с серьезной поддержкой технопарков в рамках национальных и региональных программ и проектов, включая Комплексную программу «Создание в Российской Федерации технопарков в сфере высоких технологий» [2]. Несмотря на то, что за этот период на выполнение Комплексной программы были предоставлены бюджетные средства на общую сумму 30,5 млрд. рублей (13,1 млрд.- из федерального бюджета, 17,5 млрд.из 11 региональных), аудит технопарков выявил ряд крупных проблем". К их числу относятся незавершенное строительство, низкая загруженность технопарков резидентами, невыполнение плановых показателей, невыполнение обяза- тельств отдельными регионами.

В период с 2014 г., кроме сферы высоких технологий, технопарки активно развивались как инфраструктурные площадки для поддержки развития малого и среднего предпринимательства (МСП). В результате, по данным V ежегодного обзора «Технопарки России» 2019 г., в стране зарегистрировано 156 технопарков, из них 50 действующих промышленных технопарков [6]. Уровень занятости площадей технопарков составляет по данным Ассоциации Кластеров и технопарков России $72,1 \%$, общее количество резидентов из числа субъектов МСП - 4686 единиц.

Предпринятые действия по развитию инфраструктуры МСП посредством развития технопарков не привели к росту числа организаций малого и среднего бизнеса. В ноябре 2019 года по данным ФНС показатель численности работников, занятых в сфере МСП составил 19 млн. человек (с учетом самозанятых граждан). Количество субъектов МСП оставалось примерно на одном уровне: 5,5-6 млн., одновременно число средних предприятий снизилось с 20,4 до 16,7 тысяч»**. Настораживающая тенденция наблюдается и в деятельности технопарков. Темпы роста количества резидентов незначительны и не гарантируют принципиального изменения сложившейся в сфере МСП ситуации (см. рис. 1).

Во многом интерес к технопаркам снизился из-за неэффективной деятельности управляющих компаний, не способностью их конкурировать с коворкинг-центрами, а при получении какой-либо финансовой поддержки субъектов МСП - с возрастанием документооборота и от-

\footnotetext{
" Годовой отчет «Сколково» 2019._- Режим доступа: http://sk.ru/foundation/results/annual_reports_ru/p/annual_ report_2019.aspx

*** Отчет о результатах экспертно-аналитического мероприятия «Оценка состояния гарантийной поддержки и микрофинансирования малого и среднего предпринимательства в Российской Федерации в 2015-2018 годах и первом полугодии 2019 года».- Режим доступа: http://audit.gov.ru/checks/9491
}

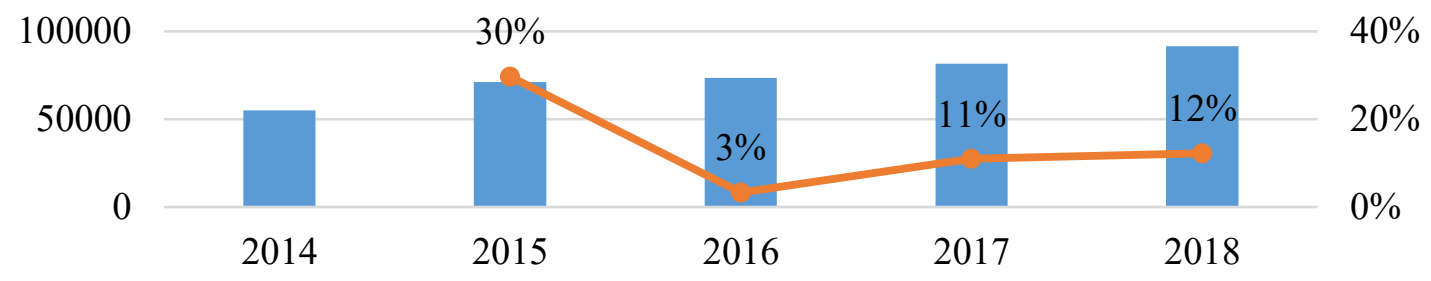

Общее количество работников у резидентов, чел

- - Темпы роста количества работников у резидентов, $\%$

Puc. 1. Динамика роста количества работников у резидентов технопарков Источник: составлено по данным [6] 
четности для резидентов.

Особой датой в истории российских технопарков стал 2010 год - время начала работы над развитием крупнейшего технопарка России инновационного центра «Сколково». Первоочередной задачей «Сколково» является поддержка стартапов, помощь в развитии инновационных проектов, продвижение технологических решений и продуктов на рынок. В результате развития экосистемы «Сколково» сегодня поддерживает более 1900 стратапов, выручка в 2018 г. составила 69,6 млрд. рублей, привлечено более 13 млрд. рублей инвестиций, создано более 30000 рабочих мест".

Как показал опыт работы «Сколково», финансирование инновационных проектов - важный, но недостаточный элемент поддержки. Именно за счет создания экосистемы - взаимосвязи образовательных организаций, производства, сервисных услуг - возможен реальный прорыв в развитии инновационного предпринимательства и трансфере инновационных технологий. Так, за каждым резидентом, получившим финансирование, закрепляется сотрудник Фонда развития Центра разработки и коммерциализации новых технологий для сопровождения проекта резидента. Этот механизм фактически обеспечивает резиденту систему навигации при прохождении маршрута от идеи до коммерциализации.

Наличие комплекса образовательных программ в бизнес-школе «Сколково»- еще один элемент инновационного центра «Сколоково». Открытый университет «Сколково» реализует программы по привлечению, вовлечению и интеграции студентов, аспирантов, молодых ученых с научно-технологическими и предпринимательскими компетенциями в инновационную экосистему России. Все эти механизмы в целом образуют систему, обеспечивающую не только комфортные условия пребывания, но и положительный результат в создании и трансфере инновационных технологий. Подобные «Сколкову» проекты достаточно дорого обходятся бюджету государства, но без создания крупных центров развития невозможно развивать качественные исследования (как фундаментальные, так и прикладные) и генерировать приток инноваций в экономику. При этом создание технопарков Middle - и Small-классов в различных регионах страны также очень важны как инструмент трансфера инновационных технологий в промышленность.

Механизмы вовлечения МСП в цепочку трансфера инновационных технологий

В настоящее время деятельность многих технопарков опирается на бизнес-модель, учитывающую ценностное предложение, формулу прибыли, процессы и ресурсы, ориентированные на развитие Управляющей компании. Клиентами при такой бизнес-модели являются резиденты (субъекты МСП), ценностное приложение заключается в создании условий для их деятельности, ключевые ресурсы - состав инфраструктуры технопарка, структура издержек определяется расходами управляющей компании на содержание технопарка, источниками доходов является арендная плата, доходы от оказания услуг резидентам, привлечение инвестиций в проекты ${ }^{* *}$ Такая модель имеет существенные ограничения, поскольку не нацелена на развитие деятельности резидентов, а ориентирована на развитие Управляющей компании технопарка. Получая финансирование от государства на развитие МСП, значительная часть поддержки расходуется именно на создание и поддержание инфраструктуры, поскольку остальные услуги оказываются резидентам на платной основе. Так Минпромторг и Минэкономразвития разработали ряд мер, рассчитанных до 2024 г., призванных обеспечить поддержку развития технопарков Российской Федерации. Субсидии выделяются на создание и (или) развитие технопарка, промышленного технопарка в целях софинансирования таких направлений как (1) строительство/реконструкция объектов инфраструктуры; (2) технологическое присоединение (подключение) к объектам электро-, газо-, водоснабжения и водоотведения; (3) оснащение объектов технопарка, промышленного технопарка офисным, лабораторным, технологическим и производственным оборудованием коллективного использования для целей предоставления в пользование резидентам - субъектам малого и среднего предпринимательства; (4) приобретение офисной мебели, электронно-

\footnotetext{
" Цифровая нация. Трансфер к интеллектуальной экономике. Годовой отчет 2019. Инновационный Центр «Сколково»

*** Модели функционирования технопарков Москвы. Волконицкая К., Институт менеджмента инновацийй НИУ Высшая школа экономики.-2016.- Режим доступа: https://www.hse.ru/data/2016/05/30/1132111309/Презентация\%20К.Волконицкой.pdf.
} 
вычислительной техники (иного оборудования для обработки информации), программного обеспечения, периферийных устройств, копировально-множительного оборудования для целей предоставления в пользование резидентам технопарка, промышленного технопарка - субъектам малого и среднего предпринимательства; (5) оплата процентов и (или) основного долга по кредитам на строительство, реконструкцию, капитальный ремонт объектов технопарка, промышленного технопарка [6]. Таким образом резиденты парка в данной группе инструментов поддержки МСП не участвует или участвует в очень ограниченном варианте.

Налоговые льготы для резидентов могут выражаться в снижении ставок налога на прибыль, транспорт, землю или имущество юридических лиц и снижении цены на аренду помещений (в первый год - скидка 50\%, второй год - 30\%). По данным сайта «Технопарки»" «арендовать помещения в технопарках могут небольшие и средние компании или крупные производства. При этом арендные ставки вполне сопоставимы со ставками в бизнес-центрах аналогичного типа и класса. Но в технопарках резиденты могут пользоваться производственными и складскими помещениями». Фактически, если предприниматель находится на стадии проектирования инновационной продукции или на более ранней стадии, то ему нет никакого смысла пользоваться услугами технопарка, можно найти более выгодные предложения в бизнес-центрах города. На начальных стадиях работы у предпринимателей нет прибыли, предприниматель не владеет земельным участком и не арендует производственные площади, так что большинство льгот являются декларативными. Сопоставимая с другими бизнес-центрами арендная плата - еще одно ограничение в конкурентоспособности технопарков. Становится понятно, что открытие технопарка как пространства имеет ограниченное значение и определяется фактическим спросом. Дискуссионным остаются вопросы организации технопарков. ГОСТ Р 56425-2015 предусматривает в числе требований к Управляющей компании организацию совместной работы с привлечением университетов, научных организаций, бизнеса, органов власти, физических лиц по созданию и функционированию инновационной и венчурно-инвестиционной системы технопарка. Однако в учредительных документах технопарков в большинстве случаев университеты и научные организации качестве учредителей отсутствуют, что является существенным препятствием для продвижения научных достижений в промышленность. Наиболее эффективной является создание технопарков с постоянным представительством научных и образовательных организаций. Такой вариант взаимодействия ассоциированных с деятельностью технопарка субъектов в обобщённом виде представлен на Рис. 2.

Управляющая компания должна выполнять услуги (1) по строительству объектов и обслуживанию пространства технопарка (электро- и газоснабжение, Интернет, ремонтные и профилактические работы по содержанию зданий, помещений, благоустройство территории). Возможно, что у отдельных Управляющих компаний могут быть компетенции для реализации деятельности по привлечению компаний-партнеров (13) и взаимодействую с инвестиционными компаниями (12) (в случае, если технопарк образован на базе действующих предприятий). Оказание различного рода консалтинговых услуг, как одного из видов деятельности Управляющей компании, осуществляется привлеченными компаниями, поскольку в большинстве случаев сотрудники Управляющей компании не обладают такими компетенциями.

Консалтинговые услуги должны оказываться в первую очередь высшими учебными заведения региона (5) и научно-исследовательскими организациями (11), а также структурами поддержки МСП (10), зарегистрированными в регионе (ТПП, Ассоциации, Центры и агентства по развитию предпринимательства, палаты и центры ремесел, маркетинговые и учебно-деловые центры и др.).

Привлечение Вузов (У2) и научноисследовательских организаций (У3) к деятельности технопарков на постоянной основе создает условия для более четкого понимания реальных и перспективных потребностей предпринимателей и выполнения научных разработок для удовлетворения этих потребностей; (2) для привлечения студентов к выполнению исследований, что дает им неоценимый опыт практической работы; (3) позволяет сформировать культуру внедрения инновационных разработок в промышленность; (4) ориентирует участников технопарков не только на поиск инновационных

" Технопарки: в чем выгода для резидентов? - Режим доступа: https://t-parki.ru/stati/119-texnoparki-v-chemvyigoda-dlya-rezidentov.html 


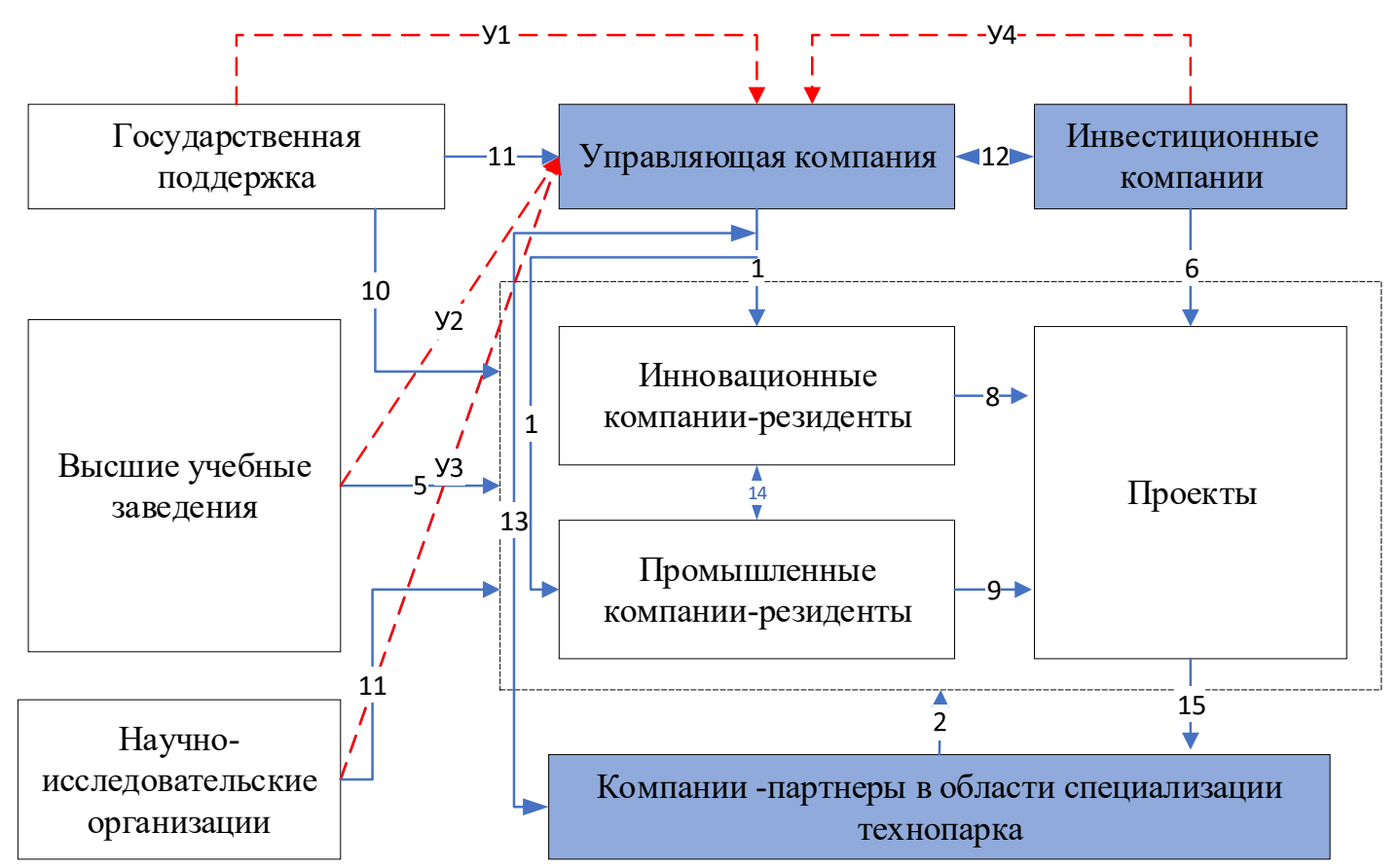

Puc. 2. Схема взаимодействия ассоциированных с технопарком субъектов Источник: Разработано авторами

решений, но и создание высокотехнологичных компаний на основе собственных исследований и профессиональных инвестиционных процессов (У4). При такой схеме взаимодействия Вузы должны создать структурное подразделение «Консалтинговый центр» для интеграции ресурсов учреждения с целью оказания консалтинговых услуг в различных областях (юриспруденции, налоговом законодательстве, охране интеллектуальной собственности, маркетинговым исследованиям, моделировании прототипов продукции и др.) и проектный офис для продвижения проектов внедрения инноваций.

Резиденты компании, работая над выполнением заявки привлеченных компаний - партнеров (2), которые на основании внутренних соглашений становятся потенциальными заказчиками разработанной продукции, получают финансирование на выполнение проектов от инвестиционных компаний, включая государственные и муниципальные фонды поддержки предпринимательства, фонды содействия кредитованию (гарантийные фонды, фонды поручительств). Результат проектной работы поступает компании-партнеру на коммерческой основе (3). Государство в виде органов региональной или муниципальной власти (У1) выполняет не только роль соинвестора, но и контро- лирует вектор развития технопарков, который должен соответствовать решению стратегических задач регионов.

Подобный механизм взаимодействия позволяет сконцентрировать ресурсы региона на развитии технопарков как структур, реально востребованных бизнесом, направить средства поддержки в сбалансированных пропорциях не только на создание инфраструктурных объектов и приобретение оборудования, но оказывать реальную поддержку резидентам.

Такая модель организации технопарков позволяет использовать вузы и научные организации как источник инновационных идей, коучинга, менторства и бизнес-тренинга, обеспечивает создание новых предприятий, исключает возможность принятия решений по финансированию проектов, не способствующих развитию МСП в регионе. Анализ преимуществ и ограничений модели представлен в таблице 1 .

Внедрение новой модели взаимодействия ассоциированных с деятельностью технопарков субъектов требует детальной разработки финансовой модели с учетом интересов всех участников образования организации системы их взаимодействия на основе современных ИТ-платформы «Технопарк». 
Таблица 1. Анализ деятельности технопарков

\begin{tabular}{|c|c|}
\hline Сильные стороны & Слабые стороны \\
\hline 1. Заинтересованность государства в развитии МСП & $\begin{array}{l}\text { 1. Сложность согласованной деятельности ассоцииро- } \\
\text { ванных с технопарком субъектов }\end{array}$ \\
\hline $\begin{array}{l}\text { 2. Наличие развитой системы поддержки МСП в ре- } \\
\text { гионах Российской Федерации }\end{array}$ & $\begin{array}{l}\text { 2. Сложность привлечения частных инвесторов на } \\
\text { начальной стадии проектов резидентов технопарков }\end{array}$ \\
\hline $\begin{array}{l}\text { 3. Наличие новых форм поддержки в рамках деятель- } \\
\text { ности технопарков: менторской поддержки, акселе- } \\
\text { рационных программ за счет интеграции с вузами }\end{array}$ & $\begin{array}{l}\text { 3. Недостаток квалифицированных кадров, в т.ч. для } \\
\text { менторской поддержки }\end{array}$ \\
\hline $\begin{array}{l}\text { 4. Выпуск инновационной продукции собственного } \\
\text { производства, востребованной на рынке }\end{array}$ & $\begin{array}{l}\text { 4. Низкая мотивация предприятий к внедрению ин- } \\
\text { новационных технологий и методов управления. }\end{array}$ \\
\hline $\begin{array}{l}\text { 5. Наличие образовательной базы и высокая актив- } \\
\text { ность вузов в процессе становления резидентов } \\
\text { технопарка }\end{array}$ & $\begin{array}{l}\text { 5. Недостаток кадров в регионах и недостаточный } \\
\text { уровень компетенций по разработке и продвижению } \\
\text { инновационной продукции. }\end{array}$ \\
\hline $\begin{array}{l}\text { 6. Наличие постоянных заказчиков за счет привлече- } \\
\text { ния предприятий-партнеров }\end{array}$ & $\begin{array}{l}\text { 6. Неравномерность развития промышленности в } \\
\text { регионах Российской Федерации }\end{array}$ \\
\hline $\begin{array}{l}\text { 7. Наличие собственных источников инновационных } \\
\text { идей }\end{array}$ & $\begin{array}{l}\text { 7. Необходимость создания бизнес-единицы в Вузах } \\
\text { для реализации консалтинговой деятельности. }\end{array}$ \\
\hline Возможности & Угрозы \\
\hline $\begin{array}{l}\text { 1. Усиление поддержки государства, принятие новых } \\
\text { программ, расширение сфер поддержки }\end{array}$ & $\begin{array}{l}\text { 1. Риск предпочтений приобретения импортной } \\
\text { продукции }\end{array}$ \\
\hline $\begin{array}{l}\text { 2. Усиление контроля финансовой поддержки за счет } \\
\text { развития и внедрения цифровых технологий }\end{array}$ & $\begin{array}{l}\text { 2. Неготовность предприятий к внедрению иннова- } \\
\text { ций }\end{array}$ \\
\hline $\begin{array}{l}\text { 3. Возрастание спроса на инновационную продукцию } \\
\text { в условиях цифовизации экономики }\end{array}$ & $\begin{array}{l}\text { 3. Сохранение рисков непрофессиональной деятель- } \\
\text { ности Управляющей компании }\end{array}$ \\
\hline 4. Интерес инвесторов к инновационным проектам & $\begin{array}{l}\text { 4. Изменение политической и экономической ситуа- } \\
\text { ции в регионе }\end{array}$ \\
\hline
\end{tabular}

\section{Заключение}

Несмотря на развитие сети организаций, задачами которых является поддержка и развитие МСП, результат нельзя признать удовлетворительным: численность субъектов МСП не растет (включая инновационное предпринимательство), не создаются новые рабочие места и, что основное, нет видимого улучшения жизни в регионах. Созданные технопарки улучшили инфраструктуру МСП, но не стали активным генератором и проводником новых технологий в сферу производства. В этой ситуации назрела задача реструктуризации неэффективных или малоэффективных технопарков. В основу реструктуризации должны быть положены меха- низмы сотрудничества технопарков с вузами и научно-исследовательскими организациями на постоянной основе. Функции технопарка должны быть распределены между учредителями таким образом, чтобы они соответствовали их компетенции и возможностям. Требование включения Вузов и научно-исследовательских организаций в состав учредителей, должно быть обязательным. Это позволит не только развиваться технопарку, но и создаст условия для продвижения инноваций, развития высокотехнологичных компаний, повлияет на процесс подготовки предпринимателей и практическому внедрению инновационных заделов вузов и научно-исследовательских организаций.

\section{Библиографический список}

1. ГОСТ Р 56425-2015 Национальный стандарт Российской Федерации технопарки Требования.- Режим доступа: http://docs.cntd.ru/document/1200121795

2. Комплексная программа «Создание в Российской Федерации технопарков в сфере высоких технологий».Режим доступа: http://docs.cntd.ru/document/901971445

3. Федеральный закон Российской Федерации «О промышленной политике в Российской Федерации (с изменениями на 2 августа 2019 года). - Режим доступа: http://docs.cntd.ru/document/420242984

4. Борисова Е.В. Инструменты формирования инновационной инфраструктуры региона для производства высокотехнологичной продукции // Креативная экономика. - 2019. - Том 13. - № 9. - С. 1783-1798. - doi: 10.18334/ce.13.9.40960. 
5. Костылева С.Ю., Макаров И.Н. Партнерство бизнеса и государства: роль системы высшего образования в инновационном развитии страны // Креативная экономика. - 2009. - Том 3. - № 5. - c. 13-21.

6. Пятый ежегодный обзор «Технопарки России - 2019» / Л.В. Данилов, Е.А. Кашинова, Е.И. Кравченко, к.э.н. М.М. Бухарова, М.А. Лабудин; Ассоциация развития кластеров и технопарков России.- М.: АКИТ РФ, 2019$110 \mathrm{c}$. 